\title{
Can Robots be Used as a Vehicle for the Projection of Socially Sensitive Issues? Exploring Children's Attitudes Towards Robots Through Stories
}

\author{
Sarah Woods, Megan Davis, Kerstin Dautenhahn \\ Adaptive Systems Research Group, School of Computer Science \\ University of Hertfordshire, $U K$ \\ \{s.n.woods, m.davis, k.dautenhahn\}@herts.ac.uk
}

\begin{abstract}
This paper presents results from a study that explored children's attitudes of robots using a qualitative approach in the form of writing stories. This approach was chosen as complimentary to quantitative methods using questionnaires that were previously used to enquire about children's attitudes and perceptions towards both physical, emotional and personality aspects of robots. Results suggest that narrative can be a useful tool to elicit children's attitudes about robots, allowing them to explore their past experiences about bullying behaviour in a novel and safe context.
\end{abstract}

Index Terms - robots, attitudes, children, narrative, stories, bullying behaviour, questionnaires.

\section{INTRODUCTION}

This study is part of a larger program of work that aims to explore the potential use of robots in educational settings for Personal and Social Health Education (PHSE) curricula activities [1]. One specific aspect of PHSE is bullying, aggression and friendship behaviour among primary school children. Bullying is a pervasive problem in UK schools which has received a lot of research and media attention over the past 10 years, and there are no anti-bullying strategies that have reported long lasting benefits [2]. We propose an innovative means of exploring bullying issues using robots as a complementary classroom based activity.

There are currently numerous robot based educational initiatives available for schools, e.g. [3], [4], [5]. Results of children's interactions with computer based technology demonstrate that children can self-reflect and project, fears, feelings, interests and role models [6]. Psychological methods are beginning to emerge as useful research techniques for roboticists to explore user perspectives of new technology [710]. While questionnaire and interview approaches are common methods used to gain adult and child views [11], the drawback of relying on these assessments is that they are usually highly structured which can mean that important data is missed and not recorded [12]. Further, these methods do not allow the subject to project their views in a creative way. Interview and questionnaire methods are viewed by some as intrusive and threatening, and can result in socially desirable responses.

As an alternative to questionnaires and interviews, insights can be gained through the medium of narrative. The importance of narrative in building our internal picture of the world, especially the social world, has been widely

\author{
Joerg Schulz \\ Psychology Department \\ University of Hertfordshire, $U K$ \\ j.schulz@herts.ac.uk
}

commented upon. It is asserted that by fitting events into a narrative pattern and telling stories to ourselves and others we construct and inhabit a meaningful and consistent world [1316]. Narrative can be seen as the fundamental way in which meaning, especially social meaning, is constructed [17, 18] and to the way it is remembered and recalled [15]. Bruner says that narrative is a way we 'domesticate surprise' [19]. We postulate that when exposing children to new experiences (such as pictures of robots) one way to get at their interpretation and understanding is to try to elicit stories.

In this study, a narrative approach using story writing about robots was used with primary school children aged 9-11 years, to capture their attitudes towards different robot designs. In addition to revealing children's perceptions about robots, a further aim of using this method was to learn about individual differences in projecting personality types, emotions and experiences onto the robots. Usually, robots give few social cues, for example expressions, if present, are fixed and simple, relating to McCloud's experience that the more iconic the presentation of a character, the more readily we identify with the character [20]. Nass \& Moon [21, 22] have found that people often imbue computers with their personality types. However, it is not known whether children assign their own personality traits, feelings and experiences onto robots.

\section{Research questions}

The focus of this study was on children's perception of different robot images and whether user individual differences in terms of gender and past bullying, and friendship experiences impacted on their judgments of various robot images, and the types of robot stories they subsequently wrote. Specifically, the research questions for this study were:

- What types of robot stories do children write?

- Are there gender and other child related differences in story writing style?

- Are children's own experiences reflected in their story composition?

- How do the results from using a narrative approach compare to results using a questionnaire design?

\section{METHOD}

Design: This study concentrated on using qualitative and quantitative methods. Children completed a questionnaire about their experiences of bullying and victimisation 
behaviour at school. They then viewed five static robot images and completed the robotics picture questionnaire for each image. Subsequently, children wrote a story in their own words about a school populated with robots rather than people, using the images that they had used to complete the robot questionnaire. Using Content Analysis, each story was coded for detailed information related to the personality and behaviour of the robots. Children's robot questionnaire responses and bullying status was examined in relation to their robot stories.

Sample: The sample reported here is a subsection of a larger sample of 159 children who participated in the questionnaire part of the study. 58 children (male: $\mathrm{N}$ : 32 (57\%), female: $\mathrm{N}$ : $24(43 \%)$ ) aged $9-11$ years (years $5 \& 6$ ) took part in the story study $(\underline{\mathrm{M}}=10.38$, SD: 0.52$)$ and have complete data sets (robot questionnaire, bullying questionnaire and robot story). Two schools participated from Hertfordshire, UK. One school was situated in a middle/upper social economic area, and the other in a lower/middle area to ensure a representative sample. Each child's reading and writing abilities were verified with the class teacher.

\section{Instruments:}

Bullying Experiences Questionnaire- This assessed children's experiences, and frequency of both physical bullying (e.g. being beaten up, threatened, having belongings stolen) and relational bullying (e.g. being called nasty names, having nasty rumours spread about you) at school over the past 6 months. Questions were based on the widely used Olweus Bullying Questionnaire [23].

Robot Pictures: Different internet sources were used to compile the robot images portfolio, consisting of 85 standardised images. A coding schedule was used to categorise the robots according to the following criteria: a) movement, b) shape, c) overall appearance (e.g. car, human, machine, animal), d) facial features, e) gender, f) functionality (e.g. toy, friend, machine). Based upon the age and cognitive abilities of the children who took part in the study, 8 groups containing 5 robot images were formed, (total $\mathrm{N}$ : 40 robot images). The remaining 35 robot images were excluded from the study due to unclear images etc. We ensured that each robot group included the different robot attributes identified during phase one of the coding scheme (different types of movement, shapes, overall robot appearance, facial features and gender).

Robot Pictures Questionnaire: 'What do you think?': This enquired about children's perceptions of different robot attributes. Section one referred to questions about robot appearance (e.g. what does this robot use to move around? What shape is the robot's body?). Section two asked questions about robot personality, rated according to a 5-point likert scale and included questions about friendliness, aggressiveness, whether the robot appeared shy, and whether the robot appeared bossy. An example question was: Do you think this robot is (or could be) aggressive?

Robot Story Task: This assessed the qualitative aspect of the study. A work sheet was used as a guidance tool for children. The instructions for the story followed the format proposed by Bruner for a story worth telling $[13,18]$ which supposes a sequence of events involving purposeful characters, and comprising a steady state, followed by some precipitating event, the restoration of a steady state and finally some terminating coda. Children were asked to plan and write a short story about one or more of the robots (could select 1-5 robot images) that they had completed questionnaires on. Children were instructed to pick their favourite robots(s) which they thought would allow them to write an interesting story about. The theme for the stories was how children thought robots would behave together in a school that was populated with robots instead of humans in terms of friendship and bullying behaviour. The story was to have a good introduction followed by two-three different paragraphs and an ending. A few suggestions were provided for the children concerning the possible characters the robots could have (e.g. aggressive robot, friendly robot), the types of actions the robots in the story might perform, and the school locations where the story might take place. Children were asked to think about the ending of the story (e.g. happy, sad).

Procedure: Groups of between 4-8 children were seated to allow the questionnaires to be completed confidentially, without distraction from other children. First, children were given the Bullying Experiences Questionnaire to complete taking approximately 5-10 minutes. A set of 5 robot images (1 of 8 categories) were randomly selected and then distributed to each child. Each child completed 5 copies of the Robot Pictures Questionnaire for each of the robot images. The robot story worksheet and a blank sheet of paper were then given to each child. The researcher went through the instructions with each group and instructed each child to select the robot images they wanted to include in their story. Children were told to write their stories using their own ideas without conferring with other members of the group. The time taken to write the stories ranged from 15-30 minutes.

Statistical Analysis: First, children were classified into bullying groups (bully, bully/victim, victim, neutral) based on their responses from the bullying questionnaire for physical and relational bullying. Frequency analysis was then computed to generate the incidence of bully roles. A detailed content-analysis scheme using dichotomous yes/no responses was devised to code the children's stories (e.g. physical aggression mentioned in story?; realistic theme to story?; robot emotions and personality expressed in the story?; happy ending to story?). The researcher rated each of the stories using the content-analysis scheme followed by an independent rater. Reliability analysis using Kappa coefficients were computed for each item. Multiple Response analysis was carried out to compare children's questionnaire and story responses about robot personality. Chi-square analysis was conducted for gender and bullying status differences in story writing styles.

\section{RESULTS}

Reliability Analysis of stories: Two independent raters coded children's robot stories using Kappa Coefficient that assesses agreement among raters, corrected for chance agreement. Kappa Coefficient values for the story items rated ranged from 0.31 to 0.95 indicating fair to near perfect agreement [24]. Values of 0.31 and 0.33 were obtained for items related to 
whether robot personality characteristics and emotions were mentioned in the stories. The two raters met to discuss the discrepancies in ratings for robot personality and emotions and reached agreement. Inconsistencies were generally due to missing descriptions of personality or emotions in the story.

The content of robot stories, what do children write about?

Most children mentioned physical aggressive acts in their robot stories (e.g. being bashed, bitten, and kicked; Nemesis robot breaks Roger's robot; punctured Speedster's tyres; ran over the victim). Fewer children cited the use of verbal abuse in their stories (e.g. teasing refrigerator robot about his yellow colour), and only 4 children (8\%) wrote about relational aggressive acts (e.g. laughing behind robot's back).

The majority of the stories were written using a fictional theme followed by an action style and science-fiction theme, and were written using a realistic style. Most children included aggressive and victim characters in their stories. Defender/helper robot characters were less frequently cited. Few children wrote about weapons being used by robots, but examples included 'big pin', 'guns, water pistol', 'metal cane', and 'lazars and rocks and stones'.

Just under half the children assigned emotional expression(s) to the $\operatorname{robot}(s)$ in their story. Some examples of emotions cited include: anger, calm, sadness, envy, fear, not feeling nice, pain, upset, annoyed, and scared. Fewer children wrote about personality characteristics related to the robots. Examples of robot personality traits include: boasting robot; clever robot, bad person, kind robot, lunar not an intelligent robot, naughty robot, shy robot and sporty robot. The majority of story endings were happy, followed by neutral, sad and moralistic (See table I for an overview of the content of children's stories).

TABLE I The content of children's stories

\begin{tabular}{|c|c|}
\hline Robot Story Quality & $\begin{array}{ll}- & \text { Average: } 54 \% \\
\text { - } & \text { Poor: } 32 \% \\
\text { - } & \text { High: } 14 \% \\
\end{array}$ \\
\hline $\begin{array}{l}\text { Number of robots in } \\
\text { stories }\end{array}$ & $\begin{array}{ll}\text { - } & \text { Mean: } 3.33(\mathrm{SD}: 1.2) \\
\text { - } & 2 \text { robots: } 23 \% \\
\text { - } & 3 \text { robots: } 35 \% \\
\text { - } & 4 \text { robots: } 21 \% \\
\text { - } & 5 \text { robots: } 19 \% \\
\end{array}$ \\
\hline $\begin{array}{l}\text { Aggression } \\
\text { mentioned in stories }\end{array}$ & $\begin{array}{ll}- & 87 \% \text { physical aggressive acts } \\
\text { - } & 40 \% \text { verbal aggressive acts } \\
\text { - } & 8 \% \text { indirect/relational aggressive acts }\end{array}$ \\
\hline Story Theme & $\begin{array}{ll}- & \text { Fictional: } 65 \% \\
\text { - } & \text { Action: } 22 \% \\
\text { - } & \text { Sci-Fi: } 12 \% \\
\text { - } & \text { Realistic: } 77 \% \\
\text { - } & \text { Fantastical: } 23 \% \\
\end{array}$ \\
\hline Characters in stories & $\begin{array}{ll}- & \text { Aggressive character: } 81 \% \\
\text { - } & \text { Victim character: } 80 \% \\
\text { - } & \text { Defender/helper character: } 37 \% \\
\end{array}$ \\
\hline $\begin{array}{l}\text { Weapons used in } \\
\text { story }\end{array}$ & - $12 \%$ cited use of weapon in story \\
\hline $\begin{array}{l}\text { Killing/dying of robot } \\
\text { in story }\end{array}$ & - $\quad 15 \%$ cited dying/killing of robot \\
\hline $\begin{array}{l}\text { Robot emotions in } \\
\text { story }\end{array}$ & - $42 \%$ cited robot emotions \\
\hline Robot personality & - $\quad 23 \%$ cited robot personality attributes \\
\hline
\end{tabular}

\begin{tabular}{|l|l|}
\hline \multirow{5}{*}{ Story ending } & $\begin{array}{l}\text { Happy: } 50 \% \\
-\quad \text { Sad: } 12 \%\end{array}$ \\
\hline$\quad$ Neutral: $32 \%$ \\
(note: does not add to $100 \%$ as some \\
children's stories had both happy and moral \\
endings etc.)
\end{tabular}

Gender differences and story-writing styles: As this study used a child-centred approach, we were interested in gender differences in the styles of robot stories written, as this could provide useful information about the perceptions and attitudes children have towards robots. Chi-square cross-tabulation tests revealed that boys $(21 \%)$ wrote more science-fiction style robot stories, and girls did not write any science-fiction themed stories $(X(1,49)=5.38, p=0.02)$. They were more likely to write using a fictional theme. There was a tendency for more girls (44\%) to include the robot role of a defender in their stories compared to boys $(24 \%)(\mathrm{X}(1,49)=2.18, \mathrm{p}=$ $0.1)$. Girls (52\%) were also slightly more likely to write about robot emotions in the stories than boys (35\%) although this was not significant. Small gender differences were also revealed for the type of story ending, girls wrote using more happy $(\mathrm{X}(1,49)=1.95, \mathrm{p}=0.1)$ and moral endings to stories $(\mathrm{X}(1,49)=2.87, \mathrm{p}=0.09)$, and boys had more neutral endings $(\mathrm{X}(1,49)=2.45, \mathrm{p}=0.1)$ (See Fig. 1 for percentages).

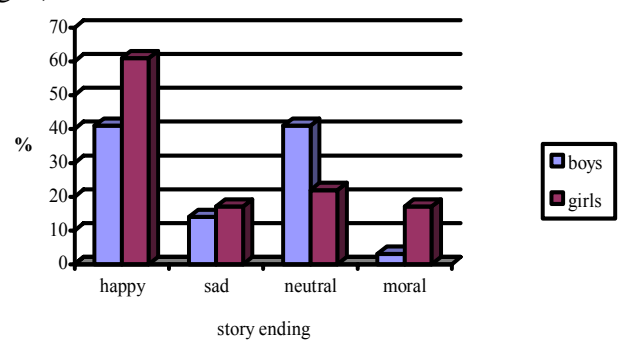

Fig. 1. Gender differences in children's story endings

The reflection of children's own experiences in stories: Bullying status and differences in story-writing styles: Children's responses to the bullying experiences questionnaire allowed us to classify children into physical and relational bullying roles (Table II). Due to the small number of children classified as bullies, analysis was carried out comparing those classified as victims versus those classified as neutrals.

\begin{tabular}{|c|c|c|}
\multicolumn{2}{|c|}{ TABLE II. Children's Bullying Status } \\
\hline Bullying Role & $\begin{array}{c}\text { Physical } \\
\text { N }(\%)\end{array}$ & $\begin{array}{c}\text { Relational } \\
\text { N }(\%)\end{array}$ \\
\hline Bully & $1(1.7 \%)$ & $2(3.5 \%)$ \\
\hline Victim & $13(22.4 \%)$ & $17(29.8 \%)$ \\
\hline Neutral & $44(75.9 \%)$ & $38(66.6 \%)$ \\
\hline
\end{tabular}

Physical Victims versus Neutrals: Some significant differences were found in robot story styles between victims and neutrals. A trend was found for children classified as victims to have a higher story writing ability rating compared to neutral children $(X(2,55)=3.89, \mathrm{p}=0.1)$. If children were classified as a physical victim, they were more likely to cite the use of verbal bullying in their robot story compared to neutral children not involved in bullying experiences (X (1, $52)=5.99, \mathrm{p}=0.01$ ) (verbal bullying in story: victim: $69 \%$ vs. neutrals: $31 \%$ ). There was a trend for neutral children to 
assign a defender role to a robot in their story more frequently than victims $(\mathrm{X}(1,52)=2.36, \mathrm{p}=0.1)$. Finally, victims were more likely to use personality traits for the robots in their stories compared to neutrals $(\mathrm{X}(1,52)=2.31, \mathrm{p}=0.1)$ (See Fig. 2 for percentages).

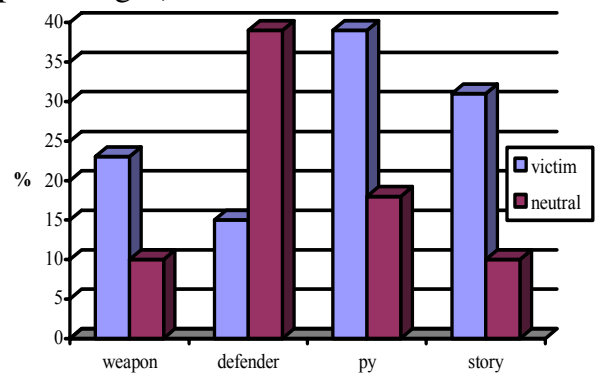

Fig. 2: Differences in story styles for victims and neutral children Key: weapon: weapon used in story, defender: defender robot in story, py: robot personality in story, story: high story writing ability

Relational Victims versus neutrals: The pattern of findings for relational victims was similar to the results for physical victims. Relational victims wrote stories of a higher quality than neutral children $(\mathrm{X}(2,54)=3.87, \mathrm{p}=0.1)$ (high story writing ability: victim: $28 \%$ vs. neutral: $8 \%$ ). There was also a trend for relational victims to cite more incidents of verbal and relational aggression between robots compared to neutrals (verbal incidents: $\mathrm{X}(1,51)=2.01, \mathrm{p}=0.1$; relational incidents: $\mathrm{X}(1,51)=2.17, \mathrm{p}=0.1)$ ). Neutrals were more likely to have a robot defender/helper in their story compared to victims $(\mathrm{X}(1,51)=2.82, \mathrm{p}=0.09)$. A different finding in comparison to the findings for physical victims was that relational victims were significantly more likely to describe emotions related to the robots compared to neutrals $(\mathrm{X}(1,51)$ $=4.84$, p 0.02) (emotions: victims: $65 \%$ vs. neutrals: $32 \%$ ). There was a trend for victims to assign personality traits to the robots more frequently than neutrals $(\mathrm{X}(1,51)=1.96, \mathrm{p}=$ 0.1 ) (personality traits: victims: $35 \%$ vs. neutrals: $18 \%$ ). No significant differences were revealed between relational victims and neutrals for story endings.

Comparing a narrative approach with questionnaire assessments: One of the major aims of using a narrative approach for this study was to determine whether children's stories were related to their responses on the robot pictures questionnaire. Results of multiple response frequency analysis revealed that children's responses were similar, although richer in detail using the story-writing approach. Table III illustrates that robots rated by children as aggressive on the robot picture questionnaire were more likely to be assigned aggressive (bully) roles in their robot stories followed by neutral roles. Table IV indicates that victim robots in the stories were more likely to have been rated by children as friendly or neutral on the robot personality questionnaire. A less clearly defined result emerged for defender robots in children's stories and the association with responses on the robot questionnaire. This is not surprising as a defender robot could be perceived by children as taking on different roles being friendly and sympathetic to a robot that is being picked on, or aggressive towards a robot that is being aggressive towards another robot (Table V). Table VI illustrates the robots that were selected for different character roles in the children's stories and the association with their responses on the Robot Pictures Questionnaire (RPQ).

TABLE III. Aggressive robots cited in children's story and association with friendly, aggressive and neutral personality responses on the RPQ

\begin{tabular}{|c|c|}
\hline Responses from RPQ & $\begin{array}{c}\text { Aggressive (bully) robots } \\
\text { cited in story (N \& \%) }\end{array}$ \\
\hline Friendly & $3(5.5 \%)$ \\
\hline Aggressive & $27(49.1 \%)$ \\
\hline Neutral & $25(45.5 \%)$ \\
\hline
\end{tabular}

TABLE IV. Victim robots cited in stories and association with friendly, aggressive and neutral personality responses on the RPQ

\begin{tabular}{|c|c|}
\hline Responses from RPQ & $\begin{array}{c}\text { Victim robots cited in story } \\
(\mathrm{N} \& \%)\end{array}$ \\
\hline Friendly & $22(41.5 \%)$ \\
\hline Aggressive & $9(17.0 \%)$ \\
\hline Neutral & $22(41.5 \%)$ \\
\hline
\end{tabular}

TABLE V. Defender robots cited in children's story and association with friendly, aggressive and neutral personality responses on the RPQ

\begin{tabular}{|c|c|}
\hline Responses from RPQ & $\begin{array}{c}\text { Defender robots cited in story } \\
(\mathrm{N} \& \%)\end{array}$ \\
\hline Friendly & $5(21.7 \%)$ \\
\hline Aggressive & $6(26.1 \%)$ \\
\hline Neutral & $12(52.2 \%)$ \\
\hline
\end{tabular}

TABLE VI. Association between robot characters children selected for their story and their responses on the RPQ: Some examples

\begin{tabular}{|c|c|c|}
\hline \multicolumn{3}{|c|}{ Robot Character in Children's Stories } \\
\hline Aggressor & Victim & Helper/defender \\
\hline $\begin{array}{l}\text { Selected } 7 \text { times } \\
\text { All children rated } \\
\text { as aggressive on } \\
\text { RPQ }\end{array}$ & $\begin{array}{l}\text { Selected } 4 \text { times } \\
\text { All children rated as } \\
\text { friendly on RPQ }\end{array}$ & $\begin{array}{l}\text { Selected } 3 \text { times. } \\
\text { All children rated } \\
\text { as aggressive on } \\
\text { RPQ }\end{array}$ \\
\hline $\begin{array}{l}\text { Selected } 4 \text { times } \\
\text { All children rated } \\
\text { as aggressive on } \\
\text { RPQ }\end{array}$ & $\begin{array}{l}\text { Selected } 3 \text { times } \\
\text { All children rated as } \\
\text { friendly on RPQ }\end{array}$ & $\begin{array}{l}\text { Selected } 2 \text { times. } \\
\text { All children rated } \\
\text { as friendly on } \\
\text { RPQ }\end{array}$ \\
\hline $\begin{array}{l}\text { Selected } 4 \text { times } \\
\text { All children rated } \\
\text { as aggressive on } \\
\text { RPQ }\end{array}$ & $\begin{array}{l}\text { Selected } 3 \text { times. } \\
\text { All children rated as } \\
\text { friendly on RPQ }\end{array}$ & $\begin{array}{l}\text { Selected } 2 \text { times. } \\
\text { All children rated } \\
\text { as neutral on } \\
\text { RPQ }\end{array}$ \\
\hline
\end{tabular}

Key: 'RPQ' = Robot Picture Questionnaire

Examples of robot images selected for children's stories and common design themes ${ }^{*}$ : Table VII illustrates the most frequently cited robots for the different character roles in the children's stories. The robot images were examined for common themes for story selection.

\footnotetext{
* Due to space limitations, only a small number of examples can be shown.
} 
Aggressive robot characters in the stories: These robots tended to be characterized by a) Movement with 2 legs, b) Silver/machine like colour, c) Mixed overall appearance (e.g. 1 humanoid, 1 animal, 1 machine), d) 2 out of the 3 most aggressive robot had some facial features, e) Had diminished/camouflaged features rather than exaggerated features.

Victim robot characters in the stories: Common features for these robots were: a) 3 out of the 7 had some human like features ( 2 legs, human body shape), b) exaggerated facial features (eyes \& mouth), c) legs as mode of locomotion, d) bright colours.

Defender/helper robot characters in the stories: Common themes for these robots included: a) 3 out of the 5 robots had some humanlike features ( 2 legs, humanlike body shape), b) facial features on 3 out of the 5 robots, c) machine like features chosen with robust appearance.

TABLE VII Robots selected the most and least frequently in children's stories

\begin{tabular}{|c|c|c|c|c|}
\hline picture & aggressor & victim & $\begin{array}{c}\text { Helper/ } \\
\text { defender }\end{array}$ & TOTALS \\
\hline \multicolumn{5}{|c|}{ Top 3 Most Frequently cited robots in children's stories } \\
\hline & $\begin{array}{l}\text { Selected } 7 \\
\text { times }\end{array}$ & $\begin{array}{c}\text { Selected } \\
1 \text { time }\end{array}$ & / & $\begin{array}{l}\text { Total }=8 \\
\text { Boys }=5 \\
\text { Girls }=3\end{array}$ \\
\hline & $\begin{array}{c}\text { Selected } 4 \\
\text { times }\end{array}$ & $\begin{array}{c}\text { Selected } \\
2 \text { times }\end{array}$ & $\begin{array}{c}\text { Selected } 1 \\
\text { time }\end{array}$ & $\begin{array}{l}\text { Total }=7 \\
\text { Boys }=5 \\
\text { Girls }=2\end{array}$ \\
\hline & $\begin{array}{c}\text { Selected } 4 \\
\text { times }\end{array}$ & $\begin{array}{c}\text { Selected } \\
2 \text { times }\end{array}$ & / & $\begin{array}{l}\text { Total }=6 \\
\text { Boys }=3 \\
\text { Girls }=3\end{array}$ \\
\hline \multicolumn{5}{|c|}{ The least frequently cited robot in children's stories } \\
\hline & & $\begin{array}{c}\text { Selected } \\
1 \text { time }\end{array}$ & & $\begin{array}{l}\text { Total }=1 \\
\text { Boys }=1 \\
\text { Girls }=0\end{array}$ \\
\hline
\end{tabular}

\section{DISCUSSION}

The current study explored children's attitudes towards robots using a narrative approach to determine the possibility of using robots as a vehicle for projecting socially sensitive issues such as bullying behaviour at school. Research question one enquired about the types of stories that children wrote in terms of the characters present, story themes, robot emotions and personality, and the types of story endings. The results illustrate that children's story composition varied in terms of the overall themes, personality and emotion characteristics of the robots, and the story endings.

It was not a surprising result that boys wrote more science-fiction themed robot stories compared to girls. Boys are likely to have been exposed to more media outlets such as film and computer games that depict science fiction themes compared to girls, and often such films are targeted towards a more male oriented audience. The fact that more girls assigned emotions to the robots could indicate that they viewed robots as having humanlike emotion capabilities and for this age group, girls are also more developed emotionally than boys which could also contribute to the result. This finding is also related to story endings where more girls had happy and moral endings, but boys tended to have neutral endings which were not emotionally charged. The fact that gender differences emerged in story styles has implications for using narrative as a form of exploring children's own experiences about socially sensitive issues in an imaginative form that they feel comfortable and at ease with. It should be emphasised that although it is sometimes assumed that robots are more oriented towards a male audience, both boys and girls in the current study were engaged and excited about using a novel approach with robots to explore bullying issues. None of the children refused to participate, even those children who found writing a more challenging task.

Using a narrative approach highlighted some selfidentification between the children and the nature of the robot descriptions in the stories. For example, children who were victims were more likely to cite the use of verbal aggression between robots in the stories which could be a reflection of their own experiences. They were also more likely to describe robot personality traits; these were frequently about the robot being scared or frightened and could also be a manifestation of previous incidents. It seems that using the robots to write stories enabled children to explore some of their own experiences. The fact that they were able to convey some aspects of their previous experiences, and associated emotion and personality traits could have future directions for the use of robotics in therapeutic and educational settings in schools. For example, Personal, Health and Social Education (PHSE), which is a compulsory part of the UK schools curriculum addresses issues such as bullying and victimisation behaviour. A popular approach is to use 'circle time' where children sit in a circle and work through different social issues using role play and game sessions with the teacher. Using robot interactions and demonstrations to explore some of the issues involved in bullying and friendship problems could provide a novel and innovative tool for teachers, and children could interact on an individual or group basis. Further, concerns have been conveyed that a child who is repeatedly victimised might not benefit from 'circle time' activities as the bully could be sitting among the group and intimidating them. The results of this study provide some evidence that using robots and a narrative approach to explore socially sensitive issues could provide children with a fun, novel and non invasive environment. Individual and group activities could be developed using the robot narratives to have more in depth sessions about bullying behaviour.

The finding that victimised children expressed in their stories that the robots had emotions more frequently than neutral (non-victimised) children did is interesting in relation to other research studies. A recent study [25] revealed that relational victims had much poorer emotion recognition abilities compared to bullies and neutral children. Results were discussed in light of the repetitive nature of victimisation and the fact that victims had poor emotion recognition skills could have perpetuated being bullied. However, using the robots for a narrative approach in this study revealed that victims seem to frequently refer to emotions and emotion expression, although we cannot be sure that these were 
directly related to their own experiences. This suggests that although victims might have problems recognising emotions in others, they are able to discuss their own emotions. These two findings have possible implications for the development of future bullying intervention initiatives that focus on emotion training, discussing emotional experiences and feelings, and self-esteem training in terms of dealing with different social situations for victims. The use of robots and narrative could be a useful tool for such interventions.

Another key aim of the current study was to compare two different approaches, questionnaire and narrative methods for exploring children's perceptions and attitudes towards different robots. When the content of children's stories were compared with their questionnaire responses for the Robot Pictures Questionnaire, findings were largely consistent. For example, robots that were rated as being friendly on the questionnaire were included in the robot stories as victim characters, whereas robots that were rated as being aggressive on the questionnaire were included as bully characters in the stories. It seems that both narrative and questionnaire approaches have advantages for exploring children's perceptions of robots and both methods could provide useful design implications. The advantage of using questionnaires is that they are economical both in terms of cost and time to administer. Analytical procedures for questionnaires are also quicker and more highly structured allowing for quantitative data with large samples. However, the advantages of using narrative are that they are less invasive which reduces the possibility of socially desirable responses and allows children to make sense of their own experiences and attitudes about bullying behaviour and robots in an imaginative and fun way. Using narrative also has educational implications in terms of children developing more competent writing skills.

A number of limitations of the current study should be discussed including the fact that static images of robots were used for children to write narratives. Our future studies plan to use live human-robot interactions to explore children's attitudes towards different robot appearances and behaviours and whether results using a narrative approach can be replicated. It would also be interesting to compare the use of robots to explore socially sensitive issues with for example virtual learning environments using a narrative approach. This study relied on self-reports of children's bullying experiences which could have led to the small number of bullies due to socially desirable responses. Future studies should consider using peer-nomination or teacher assessments to gain data about bullying status. However, we were interested in self perceptions, which is why a self-report questionnaire was used.

To conclude, the current study described using a questionnaire and narrative approach to elicit children's attitudes about different robot images, and the potential use of robots as a tool to explore socially sensitive issues such as bullying behaviour. The results suggest that children enjoyed using robots within a narrative context and that it was a useful tool to elicit children's attitudes about different robots which could provide useful design implications. Further, the robot stories allowed children to explore their own experiences of bullying behaviour in terms of emotions and personality characteristics. The potential use of robots for future antibullying initiatives is discussed.

\section{ACKNOWLEDGMENT}

We would like to thank High Beeches school, St. Albans, UK and Applecroft school, Welwyn Garden City, UK for participating in this study.

\section{REFERENCES}

[1] S. Woods, K. Dautenhahn, \& J. Schulz, "The design space of robots: Investigating children's views," Proc. Ro-Man, Japan, 2004, pp. 47-52.

[2] S. Woods \& D. Wolke, "Does the content of anti-bullying policies inform us about the prevalence of direct \& relational bullying behaviour in primary schools?" Educational Psychol., vol. 23, pp.381-401, 2003.

[3] F. G. Martin, D. Butler, \& W. M. Gleason, "Design, story-telling, and robots in Irish primary education," presented at IEEE Systems, Man and Cybernetics Conference, Nashville, Tennessee, USA, 2000.

[4] J. Montemayor, A. Druin, and J. Hendler, "From pets to storyrooms: Constructive storytelling systems designed with children, for children," in Socially intelligent agents: Creating relationships with computers and robots, K. Dautenhahn, A. Bond, L. Canamero, and B. Edmonds, Eds. Norwell, Massachusetts, USA: Kluwer Academic Publishers, 2002, pp. 205-212.

[5] A. Druin, "The role of children in the design of new technology," Behaviour and Information Technology, vol. 21, pp. 1-25, 2002.

[6] M. U. Bers and J. Cassell, "Children as designers of interactive storytellers: "Let me tell you a story about myself."" in Human cognition and social agent technology, K. Dautenhahn, Ed. Amsterdam: John Benjamins Publishing Company, 2000, pp. 61-83.

[7] P. H. Kahn (Jr.), B. Friedman, D. R. Perez-Granados, N. G. Freier, "Robotic pets in the lives of preschool children," CHI, 2004.

[8] M. Scopelliti, M. V. Giuliani, A. M. D'Amico, \& F. Fornara, "If I had a robot at home. Peoples' representation of domestic robots," in Designing a more inclusive world, S. Keates, J. Clarkson, P. Langdon, and P. Robinson, Eds. Cambridge, UK: Springer, 2004, pp. 257-266.

[9] B. Friedman, P. H. Kahn (Jr.), \& J. Hagman, "Hardware companions? What online AIBO discussion forums reveal about the human-robotic relationship," Digital Sociability, vol. 5, pp. 273-280, 2003.

[10] P. Dario, E. Guglieimelli, \& C. Laschi, "Humanoids and personal robots: Design and experiments," Journal of Robotic Systems, vol. 18, pp. 673$690,2001$.

[11] A. N. Oppenheim, Questionnaire design, interviewing and attitude measurement. London: Continuum, 2001.

[12] A. Field \& G. Hole, How to design and report experiments. London: SAGE publications, 2003.

[13] J. Bruner, Actual Minds, Possible Worlds: Harvard University Press, 1986.

[14] J. Bruner, Acts of Meaning: Harvard University Press, 1990.

[15] R. C. Schank, Tell Me a Story: Narrative and Intelligence: Northwestern University Press, 1990.

[16] C. Linde, Stories, the creation of coherence: Oxford Press, 1993.

[17] J. Bruner and C. Feldman, "Theories of mind and the problem of autism," in Understanding other minds: perspectives from autism., S. Baron-Cohen, Ed. Oxford: Oxford University Press, 1993.

[18] K. Dautenhahn, "The Origins of Narrative: In Search for the Transactional Format of Narratives in Humans and Other Social Animals.," International Journal of Cognition and Technology: Coexistence, Convergence, Co-evolution, vol. 1, pp. 97-123, 2002.

[19] J. Bruner, Making Stories: Law, Literature, Life.: Farrar, Straus and Girou, 2002.

[20] S. McCloud, Understanding Comics, the Invisible Art: Harper Perennial, 1993.

[21] C. Nass and Y. Moon, "Machines and mindlessness: Social responses to computers," Journal of Social Issues, vol. 56, pp. 81-103, 2000.

[22] C. Nass, Y. Moon, B. J. Fogg, B. Reeves, and D. Dryer, "Can computer personalities be human personalities?" International Journal of Computer Studies, vol. 43, pp. 223-239, 1995.

[23] D. Olweus, "Bullying at school: What we know \& what we can do." Oxford: Blackwell Publishers, 1993.

[24] J. Landis and G. G. Koch, "The measurement of observer agreement for categorical data," biometrics, vol. 33, pp. 159-174, 1977.

[25] S. Woods \& D. Wolke, "Emotion Recognition Abilities and Empathy in Bullies and Victims," manuscript in preparation. 